\title{
Effect of Additives on the Performance of Lead Acid
}

\section{Batteries}

Lankipalli Rekha, Manne Venkateswarlu, Kurivella Suryanarayana Murthy and Mandava Jagadish

Research \& Development, Technology, Amara Raja Batteries Ltd., Andhra Pradesh 517 520, India

Received: June 18, 2015 / Accepted: August 03, 2015 / Published: October 31, 2015.

\begin{abstract}
Effect of titanium dioxide $\left(\mathrm{TiO}_{2}\right)$ and carbon additives in the respective positive and negative material properties and the influence on the performance of the battery were investigated. The electrode samples were characterized by BET (Brunauer Emmett Teller), XRD (X-ray diffractometer), SEM (scanning electron microscopy) and EIS (electrochemical impedance spectroscopy) to understand the surface area, phase, structure, morphology and electrical conductivity of the respective electrode material. The surface area was obtained as $2.312 \mathrm{~m}^{2} \cdot \mathrm{g}^{-1}$ and $0.892 \mathrm{~m}^{2} \cdot \mathrm{g}^{-1}$, respectively for $12 \%$ of activated carbon in the expander of negative and $0.70 \%$ of $\mathrm{TiO}_{2}$ (Titanium dioxide) in the PAM (positive active material). The structural analysis reveals an increase in the tetrabasic lead sulfate and also evidenced by well grown crystals in the PAM with the $\mathrm{TiO}_{2}$, respectively obtained by XRD and SEM techniques. The impedance spectra analysis shows an increase of electrical conductivity of negative active mass with temperature. The battery results showing two fold enhancements in the charge acceptance were attributed to the high surface area activated carbon in the NAM (negative active material). The materials properties of electrodes and their influence on the battery performance were discussed.
\end{abstract}

Key words: Titanium dioxide, carbons, charge acceptance, lead acid battery.

\section{Introduction}

Lead acid batteries are the most versatile and reliable power source for cranking applications. These batteries are remaining as central electric power for starter and also ideal stop starts due to its safety and economy. For high voltage and power, assist functions of hybrid electric vehicle require high power storage systems to sustain repeated charge and discharge reactions even at high rate discharge or under the PSoC (partial state of charge) [1-3]. The present performances of lead acid batteries are not adequate for emerging applications. Therefore, research attention has been focused on to improve the specific energy, charge acceptance, rate capability and cycle life of the VRLA (valve regulated lead acid) battery.

The lower specific energy is one of the major limitations of lead acid battery mainly due to poor

Corresponding author: Manne Venkateswarlu, Ph.D., AGM (assistant general manager), research fields: electrodes and electrolytes materials, rechargeable batteries and nanomaterial.E-mail: mvu@amararaja.co.in.
PAM (utilization of the positive active material) and also high atomic weight of the lead [4]. Several studies have been carried out on the positive active material by reducing the weight or improving the adhesive properties and or exploring intelligent additive, nanowires, etc., for better utilization of the positive active material [4-7]. Similarly, efforts were also made to improve charge acceptance and cycle life of battery by eliminating sulfation in the negative electrode. The progressive accumulations of sulfation with cycling may shorten the life or fail the battery. Nakamura, et al. [8] had successfully achieved in eliminating the sulfation in the negative by increasing the carbon content which further enhanced the life of the battery. The carbon of different grades is obviously an additive in the negative and was found to have beneficial effects on the material properties [9-18]. Some of these benefits are: improving conductivity of active mass, facilitating the formation of small isolated lead sulfate crystals, impeding the reaction of hydrogen evolution, and also acting as an electro-osmotic pump to diffuse acid into 
the negative electrode.

In this paper, an attempt has been made to develop battery with enhanced capacity, charge acceptance and life of the battery for emerging automobile applications. The titanium dioxide $\left(\mathrm{TiO}_{2}\right)$ and the carbon materials are selected as additives in the respective positive and negative electrodes and characterized. The effects of additive on the material properties and performance of batteries were studied.

\section{Experiments}

\subsection{Preparation of Positive and Negative Electrodes}

The positive active material was prepared by mixing up of lead oxide with different loading of $x \% \mathrm{TiO}_{2}(x=$ $0.35,0.70$ and 1.40). The DM (demineralized water) water and sulfuric acid were added to the dry mixture of active material under controlled temperature. Standard procedure was followed to obtain homogeneous paste of positive oxide. Similarly, the negative active material was prepared by mixing up of lead oxide with different grades of carbons (carbon black, black pearl and activated carbon). The loading of the carbon was $12 \%$ in the expander of negative electrode. The DM water and sulfuric acid content was added appropriately to the mixture and the standard procedure was followed to obtain homogeneous paste recipe of negative. The positive and negative oxide paste were applied on grids separately and then allowed to cure \& dry under controlled temperature and humidity. The resultant electrodes were characterized and also used for assembling VRLA battery.

\subsection{Characterization of Electrode Materials}

The cured electrode materials were analyzed by chemical method to estimate the free lead, lead oxide and lead sulfate content. The surface area of the different grades of carbon powders and modified electrodes was estimated by the BET (brunauer emmett teller) method (Coulter SA3100). The structural studies were carried out by XRD (X-ray diffractometer) (PANalytical). The XRD spectra were recorded with $\mathrm{CuK} \alpha$ radiation $(1.5418 \AA)$ in the $2 \theta$ range from $10^{\circ}$ to $80^{\circ}$ and analyzed by $\mathrm{X}$ 'pert software.

The morphology of the electrodes was mapped by SEM-EDS (scanning electron microscopy coupled with energy dispersive spectroscopy) (HitachiS-3400N). SEM images and SEM-EDS spectra were recorded and mapped to understand the morphology of the crystals and elemental distribution in the respective electrodes. The EIS (electrochemical impedance spectroscopy) (novo-control) was used to evaluate the electrical conductivity of the electrode and data were analyzed by WinFIT software.

\subsection{Design and Testing of Batteries}

The VRLA battery configuration with rating of $5 \mathrm{Ah}$ was selected for testing. The VRLA battery made up of modified positive and modified negative electrodes were coupled with regular negative and regular positive electrodes, respectively. The AGM (adsorbed glass mat) was used as separator to complete the VRLA design. The aqueous sulfuric acid with standard specific gravity was used as electrolyte. The electrical tests were carried out using LCN (life cycle network) circuits (Bitrode) and multi-functional electrochemical analyzer (Wonatech). The batteries were tested as per applicable JIS (Japanese Industrial Standard).

\section{Results and Discussion}

\subsection{Chemical Analysis and Surface Area Studies}

The cured electrode materials consist of several lead compounds such as free lead, oxides, sulfates, etc. The PAM (positive active material) that consists of $x \%$ of $\mathrm{TiO}_{2}$ was analyzed by chemical method to ensure that, the free lead, sulfate and density contents were within the specification. The surface area of PAM with $x=$ $0.70 \%$ of $\mathrm{TiO}_{2}$ was $0.892 \mathrm{~m}^{2} \cdot \mathrm{g}^{-1}[16]$.

The chemical analysis was also carried on the NAM (negative active material) samples consisting different grades of carbon. The lab results were found to be within the specification. The surface area analysis was 
carried out on the carbon materials as well as NAM with different carbons. The surface area of carbon black, black pearls and activated carbon was found, respectively $82 \mathrm{~m}^{2} \cdot \mathrm{g}^{-1}, 1,450 \mathrm{~m}^{2} \cdot \mathrm{g}^{-1}$ and $1,950 \mathrm{~m}^{2} \cdot \mathrm{g}^{-1}$. The highest surface area of the NAM with activated carbon was found as $2.138 \mathrm{~m}^{2} \cdot \mathrm{g}^{-1}$.

\subsection{Structural and Morphology Studies}

During curing, electrodes undergo chemical reactions to convert the free lead into the basics sulfates of different forms such as mono, tri and tetra basic. The formations of tri and tetra basic sulfate in the positive electrode would be beneficial effect on the capacity and life of the battery, respectively. The XRD spectra were recorded for all cured positive electrodes consisting of $x \%$ of the $\mathrm{TiO}_{2}(x=0.35,0.70$ and 1.40) and observed XRD profiles are shown in Fig. 1.

The lead, lead oxide, lead dioxide and tribasic lead sulfates (3BS) and tetrabasic lead sulfate (4BS) were calculated quantitatively by matching the observed spectral data with selected JCPDS (joint committee on powder diffraction standard) data. The selected JCPDS data are: 01-087-0663 (Pb), 01-078-1666 (PbO), 01-072-2102 ( $\left.\mathrm{PbO}_{2}\right), \quad 01-088-0552$ (3BS) and $00-023-0333$ (4BS). The concentration of 4BS was $34 \%, 51 \%$ and $49 \%$, respectively obtained in the positive electrode consisting $0.35 \%, 0.70 \%$ and $1.40 \%$ of $\mathrm{TiO}_{2}$. The 4BS was found appreciably higher which was obtained at higher temperature and humidity $[11,12]$. The presence of 4BS in the positive electrode enhances the strength of electrode by interconnected structure and also porosity in the positive electrode [12]. The presence of 4BS in the PAM which enhance the cycle life of the battery may be due to improved structure stability and also better access of the acid throughout the electrode. Further, the crystallite size was calculated using Scherer's formula and was found as 25.70, 40.53 and $33.47 \mathrm{~nm}$, respectively for $0.35 \%$, $0.70 \%$ and $1.40 \%$ of $\mathrm{TiO}_{2}$ in the PAM. The larger crystals have smaller surface area and vice versa. The crystals are larger for the $x=0.70 \%$ of $\mathrm{TiO}_{2}$ in $\mathrm{PAM}$ due to high concentration 4BS which is expected to be lower surface area, as evidenced by surface area analysis. The surface area of PAM was found to be relatively lower as compared to NAM. The present XRD and BET results are complementary to each other. The structure of the electrode plays a significant role in enhancing the cycle life of the battery for repeated cycling.

The electrode structure build with well-defined crystals, optima size and shape and uniform distribution of elements are desired ways to improve the material properties of battery. The SEM images for different $x \%$ of $\mathrm{TiO}_{2}$ in the PAM were recorded and the typical SEM image of the positive electrode with $0.70 \%$ of $\mathrm{TiO}_{2}$ in PAM was shown as inset in Fig. 2.

The SEM images were found larger crystals and results are consistent with structural analysis by XRD where the structure consists of predominately 4BS. Further, SEM-EDS mapping was carried out to understand the distribution of the elements in the respective electrodes. The SEM-EDS mapping for PAM with $0.70 \%$ of $\mathrm{TiO}_{2}$ is shown in Fig. 2. It clearly shows the presence of titanium and its distribution throughout the electrode.

The SEM images on the NAM were also analyzed and typical SEM image of activated carbon in the

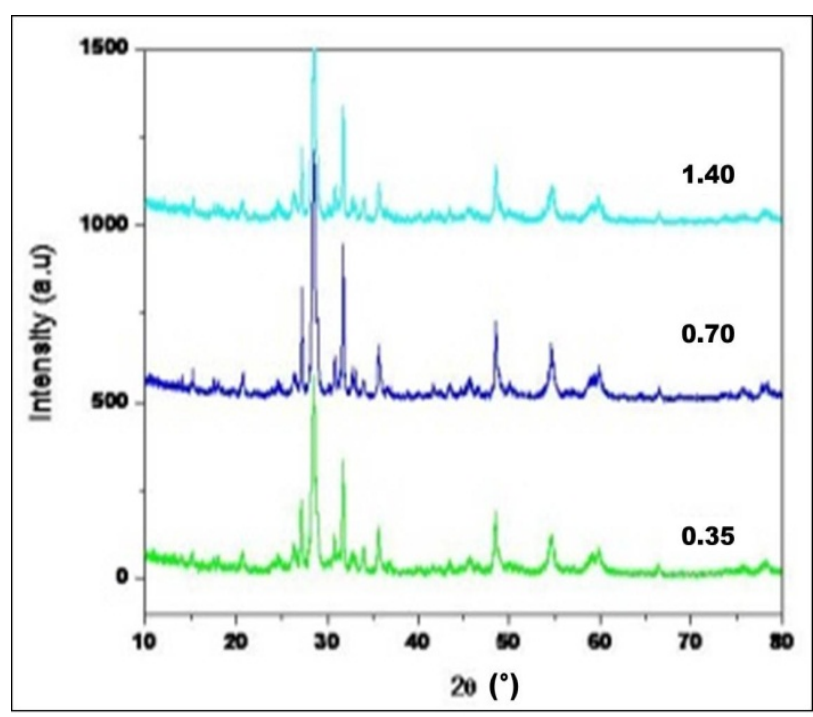

Fig. 1 The XRD spectra of the positive electrode with $x \%$ of $\mathrm{TiO}_{2}$. 


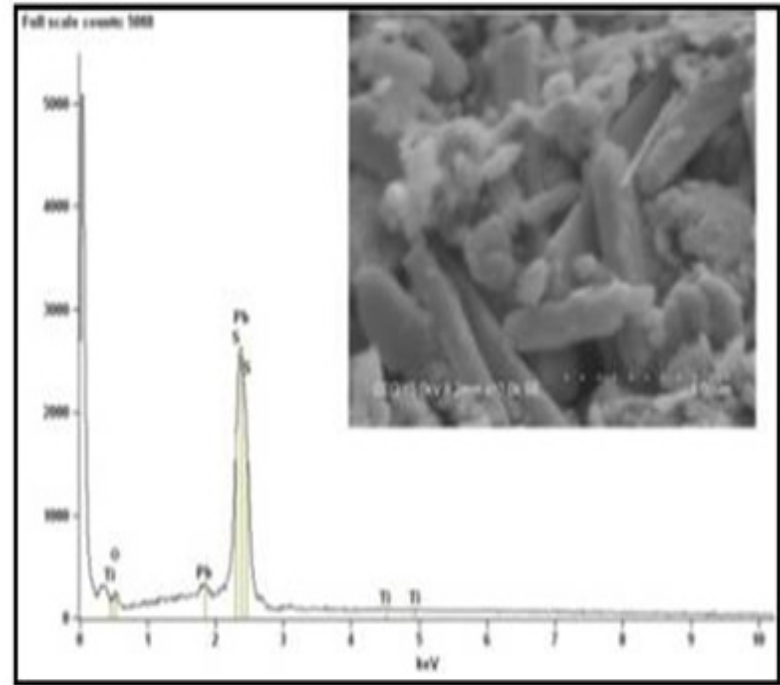

Fig. 2 The SEM-EDS spectral mapping of the PAM with $0.70 \%$ of $\mathrm{TiO}_{2}$ (inset figure is the SEM image).

expander of negative is shown as inset in Fig. 3. The SEM image shows the well-defined crystals with much smaller in size and shape. The smaller crystals have larger surface area and vice versa. The improved material properties were attributed to the presence of high surface area $\left(1,950 \mathrm{~m}^{2} \cdot \mathrm{g}^{-1}\right)$ activated carbon in NAM which controls the sulfate crystals. The SEM-EDS spectral mapping of the NAM with activated carbon is shown in Fig. 3. The SEM-EDS spectral analysis confirms the presence of the carbon in the NAM and also uniform distribution throughout the NAM electrode $[15,16]$.

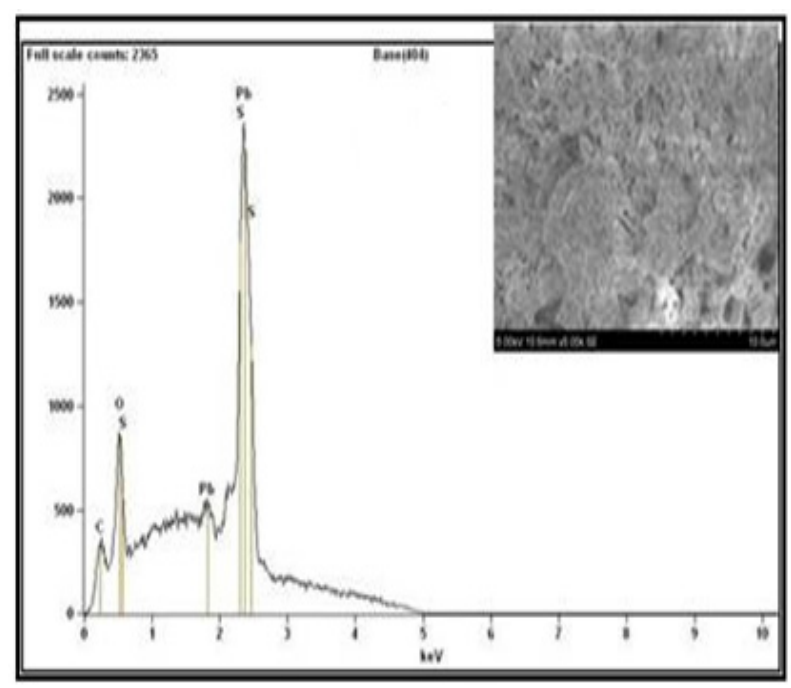

Fig. 3 The SEM-EDS spectral mapping of the NAM with activated carbon (inset figure is the SEM image).

\subsection{Impedance Spectroscopy Studies}

The EIS is very informative tool to understand the physical parameters of the materials. The EIS studies have been carried out on the NAM with activated carbon at ambient and also at different temperatures. The impedance spectra of NAM consisting activated carbon at different temperatures are shown in Fig. 4.

Fig. 4 clearly shows the formation of semi-circle on the NAM within the temperature range. It is worth to mention that, the semi-circle of active mass changes with temperature indicates decreasing the bulk resistance $\left(R_{b}\right)$ of the NAM with temperature. In other words, the electrical conductivity of the active mass increases with temperature and was attributed to the presence of activated carbon in the NAM.

\subsection{Battery Studies}

The influence of the positive active material properties on the battery was studied on VRLA battery with modified positive (with $\mathrm{TiO}_{2}$ ) electrode and regular negative electrode. The AGM separator was used to separate the electrodes and also avoid internal shorting. The aqueous sulfuric acid with standard specific gravity was used as electrolyte. The battery parameters such as capacity, HRD (high rate discharge) and CA (charge acceptance) were evaluated as per JIS standard [16]. The electrical performance of the batteries

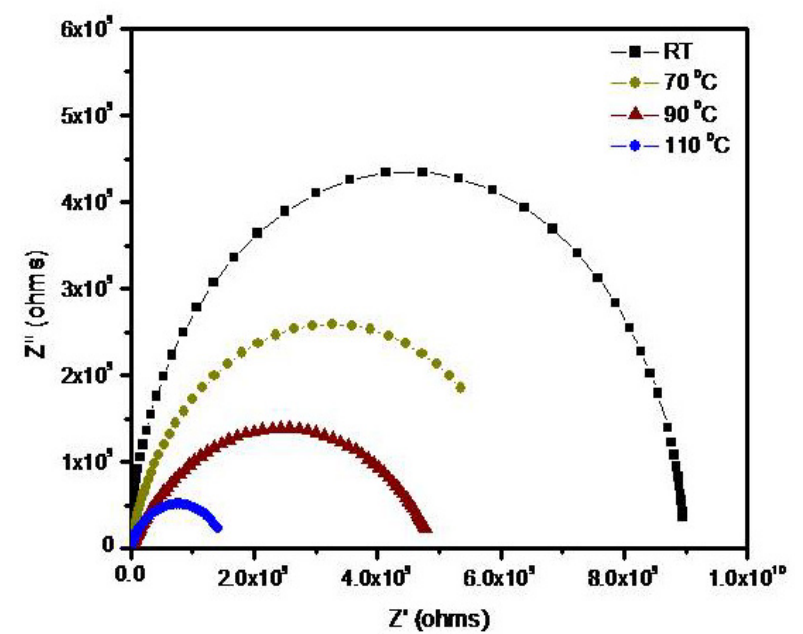

Fig. 4 Impedance spectra of the NAM with activated carbon. 
consisting $x \%$ of $\mathrm{TiO}_{2}$ in PAM is shown in Fig. 5 .

Fig. 5 shows the significant improvement in the charge acceptance of the battery of the PAM with $x \%$ of $\mathrm{TiO}_{2}$. Further, the capacity of the battery meets the standard but was found lower values in case of HRD may be due to surface area and electrical properties of the positive active materials.

In order to understand the role of different grade carbon in the expander of negative electrode, the VRLA battery with modified negative (carbon) and regular positive and electrodes were wrapped with AGM separator and aqueous sulfuric acid was used as electrolyte. The battery parameters such as capacity, HRD and CA of the battery were evaluated as per the JIS standard. The electrical performance of the battery with different grades of carbons in NAM is shown in Fig. 6.

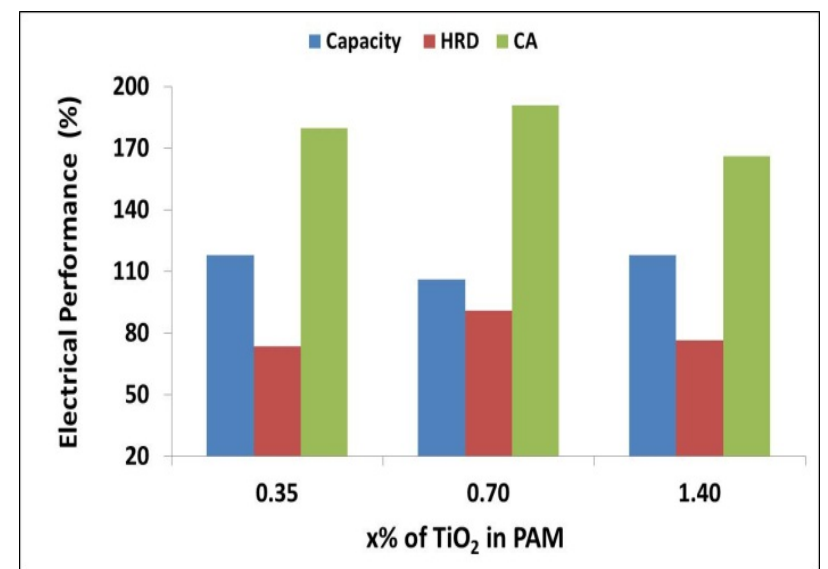

Fig. 5 The electrical performance of battery consisting $x \%$ of $\mathrm{TiO}_{2}$ in PAM.

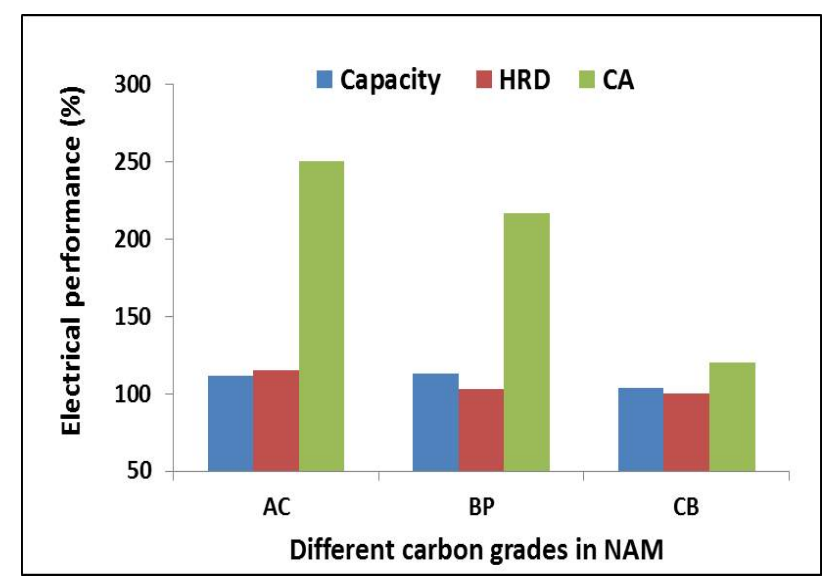

Fig. 6 The electrical performance of battery with different grades of carbon in NAM.

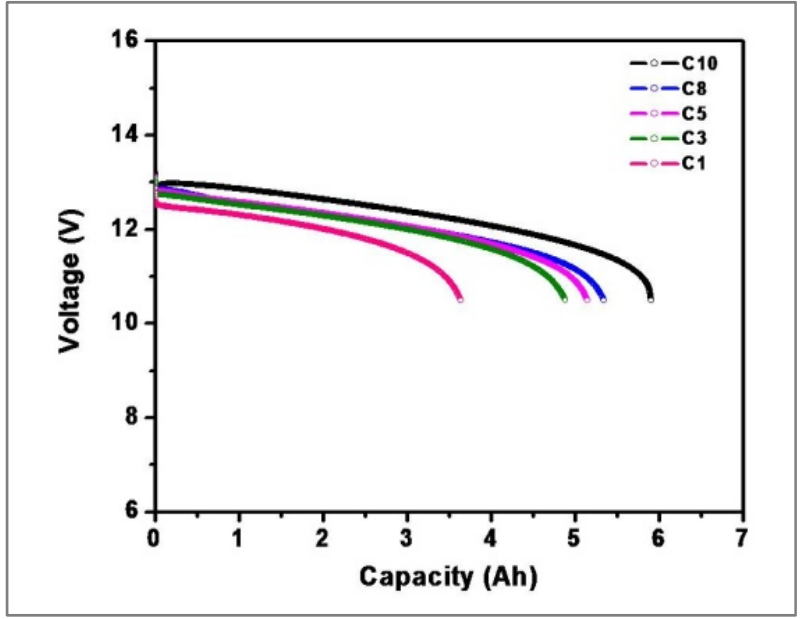

Fig. 7 Discharge profile of the battery at different C-rates.

From Fig. 6, it is confirmed that, the capacity and HRD results were found to be marginal whereas significant improvement, by two fold, of charging acceptance of the negative. The two fold enhancement was attributed to the presence of high surface area $\left(1,950 \mathrm{~m}^{2} \cdot \mathrm{g}^{-1}\right)$ activated carbon improves the material properties of the active mass and also alleviate the sulfation. Therefore, the battery consists of negative active material blended with activated carbon can deliver high energy and power and expected to meet the electric power requirement for emerging automobiles.

Further, these batteries were evaluated at different loads at lab scale to understand the rate capability of batteries. The rate capability of the batteries could be achieved either by reducing the thickness of the electrodes or conductive additives in the electrodes. These batteries with negative consists of activated carbon were tested at different C-rates. The typical discharge profiles of the batteries are shown in Fig. 7. The discharge capacities were obtained at $0.10 \mathrm{C}$ and 1.0 $\mathrm{C}$ are $5.8 \mathrm{Ah}$ and 3.5 Ah, respectively [16].

\section{Conclusions}

The presence of the titanium dioxide in the positive active material was found to be beneficial in enhancing the tetra basic lead sulfate which in turn enhances the life of the battery. The high surface area activated carbon in the negative electrode improves the capacity 
and HRD marginal. Apart from enhanced electrical conductivity of the active mass, a profound impact was observed on the charge acceptance of the battery and was attributed to carbon in the negative electrode. It was concluded that, the selective grade of carbon in the negative electrode pronounced a beneficial effect on the performance of the lead acid batteries for emerging automobile applications.

\section{Acknowledgments}

Authors are grateful to the Management of Amara Raja Batteries Ltd., for their constant encouragement. Authors are grateful to Dr. Nallani Satyanarayana, Pondicherry University for extending the experimental support and data analysis.

\section{References}

[1] Mosley, P. T., Rand, D., and Monahov, B. 2012. "Designing Lead Acid Batteries to Meet Energy and Power Requirement of Future Automobiles." J. Power Sources 219 (December): 75.

[2] Karden, E., Shinn, P., Bostock, P., Cunningham, J., Schoultz, E., and Daniel, K. 2005. "Requirements for Future Automotive Batteries-A Snapshot." J. Power Source 144 (2): 505.

[3] Ebner, E., Burow, D., Panke, J., Borger, A., Feldhoff, A., Atanassova, P., Valenciano, J., Wark, M., and Ruhl, E. 2013. "Carbon Blacks for Lead Acid Batteries in Micro-Hybrid Applications-Studied by Transmission Electron Microscopy and Raman Spectroscopy." J. Power Source 222 (January): 554.

[4] Moncada, A., Mistretta, M. C., Randazzo, S., Piazza, S., Sunseri, C., and Inguanta, R. 2014. "High Performance of $\mathrm{PbO}_{2}$ Nanowires Electrodes for Lead Acid Battery." $J$. Power Sources 256 (June): 72.

[5] Mcallister, S. D., Patankar, S. N., Cheng, I. F., and Edwards, D. B. 2009. "Lead Dioxide Coated Hollow Glass Microscopeheres as Conductive Additives for Lead Acid Batteries." Scripta Materialia 61 (4): 375.

[6] Ponraj, R., McAllister, S. D., Cheng, F., and Edwards, D. B. 2009. "Investigation on Electronically Conductive Additives to Improve Positive Active Materials Utilization in Lead Acid Batteries.” J. Power Sources 189 (2): 1199.

[7] Moncada, A., Mistretta, M. C., Ranadzzo, S., Piazza, S., Sunsuri, C., and Ingnanta, R. 2014. "High-Performance of $\mathrm{PbO}_{2}$ Nanowire Electrodes for Lead-Acid Battery." $J$.
Power Source 256 (June): 71.

[8] Nakamura, K., Shiomi, M., Takahashi, K., and Tsubota, M. 1996. "Failure Modes of Valve-Regulated Lead/Acid Batteries.” J. Power Sources 59 (1-2): 153.

[9] Shiomi, M., Funato, T., Nakamura, K., Takahashi, K., and Tsubota, M. 1997. "Effects of Carbon in Negative Plates on Cycle-Life Performance of Valve-Regulated Lead Acid Batteries." J. Power Sources 64 (1-2): 147.

[10] Kazawa, A., Kawamura, T., Sato, A., Sano, M., and Brold, D. 1998. "New Colloidal and Organic Carbon Additives for Lead Acid Batteries." In Proceedings of the 13th Annual Battery Conference on the Applications \& Advances (January), 353.

[11] Boden, D. P., Loosemore, D. V., Spence, M. A., and Wojcinski, T. D. 2010. "Optimization Studies of Carbon Additives to Negative Active Material for the Purpose of Extending the Life of VRLA Batteries in High Rate Partial State of Charge Operation." J. Power Source 195 (14): 4470.

[12] Krivik, P., Mica, K., Baca, P., Tonar, K., and Poser, P. 2012. "Effect of Additives on the Performance of Negative Lead Acid Battery Electrodes during Formation and Partial State of Charge Operation.” J. Power Sources 209 (July): 15.

[13] Pavlov, D. P., and Niklov, P. N. 2002. "Lead Carbon Electrode with Inhibitor of Sulfation for Lead Acid Batteries Operation in HRPSoC Duty." J. Electrochem. Soc. 159 (8): A1215.

[14] Mosely, P. T., Nelson, P. F., and Hollenkamp, A. F. 2006. "The Role of Carbon in Value Regulated Battery Technology.” J. Power Sources 157 (1): 3.

[15] Venkateswarlu, M. 2011. "Improvement of Lead Acid Battery Performance by Nano Carbon Materials." In Proceedings of the 14th Asian Battery Conference (September), 24.

[16] Rekha, L., Venkateswarlu, M., Murthy, K. S. N., and Jagadish, M. 2014. "Influence of Carbon and $\mathrm{TiO}_{2}$ Additives on the Performance of the Lead Acid Batteries." In Proceedings of the 9th International Conference on Lead-Acid Batteries (June), 55.

[17] Sugumaran, N., Everill, P., Swogger, S. W., and Dubey, D. P. 2015. "Lead Acid Battery Performance and Cycle Life Increased through Addition of Discrete Carbon Nanotubes to Both Electrodes." J. Power Sources 279 (April): 281.

[18] Sarvanan, M., Ganesan, M., and Ambalvanan, S. 2014. "An in situ Generated Carbon as Integrated Conductive Additive for Hierarchical Negative Plate of Lead Acid Battery." J. Power Source 251 (April): 20. 